\title{
A content analysis of Chinese and American media's report on "Occupy Central" incident in Hong Kong
}

\author{
Chao $\mathrm{Ma}^{1}$ \\ ${ }^{1}$ College of Literature and Journalism, Sichuan university, Chengdu, China
}

Keywords: Frame Theory, Occupy Central, Content Analysis, New York Times, China Daily.

\begin{abstract}
Based on frame theory, this study analyzed the characteristics of China Daily and New York Times when reporting the "Occupy Central" incident in Hong Kong. The study found that there were differences in the length and types between the two media. China Daily give priority to the short comments while the New York Times preferred the news and features. In the choice of news sources, China Daily took priority to Hong Kong local residents and officials, but it did not refer to a different point of view; The New York Times was imbalanced since frequently citing the utterance of dissidents .On the present of theme, China Daily pointed out the illegality and the harmfulness of "Occupy Central" rally by adopting the consequences-effect frame and the rule of law frame while the New York Times used process frame more often to describe the rallies of the protesters. The study showed that the two newspapers reported the "Occupy Central" incident for their respective interests. The New York Times presented the opposite side of the conflict unilaterally while China Daily always serviced for the national core interests by safeguarding national sovereignty, security, development interests and Hong Kong's prosperity and stability through a lot of comments.
\end{abstract}

\section{Introduction}

On September 28, 2014, Some people in Hong Kong initiated the so-called "Occupy Central" rally, which immediately aroused the attention of the international community. For a time, the major media in the world have set their sights on this metropolis. The media usually represent certain interest groups,which has its own tendency and is always based on their different positions when choosing, producing and disseminating their information. The media in different countries often show different ways when presenting the same event. Due to the different news frame, there is a competition, compromise and obedience for discourse power [1].Thus, This paper tries to discuss the differences between Chinese and foreign media when reporting the "Occupy Central" incident in perspective of media frame theory.

\section{Literature Review}

In 1974, American sociologist Owen Goffman published a book named Frame analysis: an Essay on the organization of experience .which first proposed the concept of "frame". Since then, American scholars Gitlin in 1980 introduced the frame theory into the media research field, he defined it as "frame are principles of selection, emphasis and presentation composed of little tacit theories about what exit, what happens and what matters" [2].

Entman considered that "framing essentially involves selection and salience. to frame is to select some aspects of a perceived reality and make them more salient in a communicating text, in such a way as to promote a particular problem definition, causal interpretation, moral evaluation and/or treatment recommendation." [3]

Some scholars believe that "selection" and "reorganization" are the most important strategies to construct news frame. "Selection" includes two aspects, named emphasis and exclusion. As for the reorganization strategy, it means that news media rearrange the order of news material and give it new meaning [4].

As a macroconstruct, the term "framing" refers to modes of presentation that journalists and other communicators use to present information in a way that resonates with existing underlying schemas among their audience 
a macroconstruct, the term "framing" refers to modes of presentation that journalists and other communicators use to present information in a way that resonates with existing underlying schemas among their audience

As a macroconstruct, the term "framing" refers to modes of presentation that journalists and other communicators use to present information in a way that resonates with existing underlying schemas among their audience

A large number of scholars have found that different news frames have different effects on audience's cognition. For instance, Kahneman and Tversky found that decision problems can be framed in multiple ways that give rise to different preferences[5].De vreese has investigated the effects of different TV news frames on audience's political attitude. He found that the role of news frame was equally important with the core facts when the audience perceived political events [6].

Ghanem has broken media frame into four dimension[7]:

1. the topic of a news item(what is include in the frame)

2. presention(size and placement)

3. cognitive attributes(details of what is included in the frame)

4. affective attributes(tone of the picture)

This paper will refer to the above classification to construct research category .

\section{Research design}

This paper select the "China Daily" as object, because it has entered the international mainstream society and had a certain influence, Compared with the global prestigious media named New York Times. We have analyzed the two media's coverage about "Occupy Central" incident.

We took advantage of ProQuest data base, choosing the New York Times and China Daily as object, and retrieving "Occupy Central" as key words. in case of omission, we also visited the website of China Daily and the New York Times, Using the same keywords to search again for supplement.

The trigger of the incident was from the essay "civil disobedience is the biggest destructive weapons" written by Dai Yaoting who works at University of Hong Kong in January 16, 2013. the preliminary end of the incident is the Hong Kong police rectified Tongluowan area on December 15, 2014. Thus, we limited the search period from January 1, 2013 to December 15, 2014.

After retrievaling and filtering unrelated articles, a total of 78 articles in China Daily and 35 articles in New York Times are chosen.

In this study, each article is regarded as an analysis unit, Based on the zhangtaofu's research, we established the following encoding categories.

Length. According to the number of essay, the length of the article is divided into following aspects.

(1)Below 500 words;(2)501-1000 words;

(3)1001-1500words;(4)1501-2000words;

(5)More than 2000 words.

Types of report. Since the United States does not have the types of "correspondence" .Thus, in order to make the distinction, this study divides the types into two categories

(1) news (including feature, in-depth report, investigation)

(2) comment(including editorial and column).

News source. According to the main characteristics of the message, this paper divides the source into 15 categories

(1)Hong Kong citizens; (2)Dissident; (3)Businessman

(4)Government officials of Hong Kong;(5)Scholars;

(6)China's top national leaders; (7)Mainland citizens;

(8) Chinese government officials; (9)Overseas Chinese;

(10)Journalist; (11)Entertainers; (12)Mainland media Police;

(13)Foreigners; (14) Students; (15) Mainland medias 
Theme. According to the main contents of the reports, this study classifies the theme into the following 9 categories.

(1) Action of actors in "Occupy Central" incident.

(2) The response of the Hong Kong's government to the rally.

(3) The responses of Hong Kong's local residents to the rally.

(4) To point out the harmfulness and the illegality of the "Occupy Central" rally.

(5) Mainland residents' responses to rally behavior.

(6) The reactions of the international community to the "Occupy Central" incident in Hong Kong.

(7) The mutually dependent relationship between mainland and Hong Kong.

(8) Emphasize the position of the Chinese Central Government.

(9) Others

News frame. According to the title and main content, we summarized six news framings as follows.

(1) Process frame. It mainly describe the whole progress of the event.

(2) Outcome and effect frame. Under that frame, The news highlights economic, political and social impact brought by occupy central incident.

(3)Advice frame. This frame focuses on how to deal with the events, and discusses the possible ways to cope with it.

(4)Explanation frame. The frame is mainly to explain the origin, the background and the development direction of the event.

(5) Query frame. It mainly expose the drawbacks and questioned the intention of one side.

(6)Rule of the law frame. It mainly stressed that the public should abide by the basic law and the National People's Congress Standing Committee's decision as well as express reasonable demands based on the law.

According to the core narrative principle of each frame, two coder after training firstly extracts $30 \%$ samples for content analysis, and the Cohen coefficient of the two persons is 0.86 , which has good reliability.

\section{Results}

The length of report. We can see from Figure 1 and Figure 2, the length of each article in China Daily is mainly between the 501 to 1000 words(57.7\%)whereas the length of each article in New York Time is between the 1001 to 1500 words(54.3\%). Although the overall news number of China Daily is more than the New York Times. However, as for each article, the length of each article in New York Times is longer than China Daily .

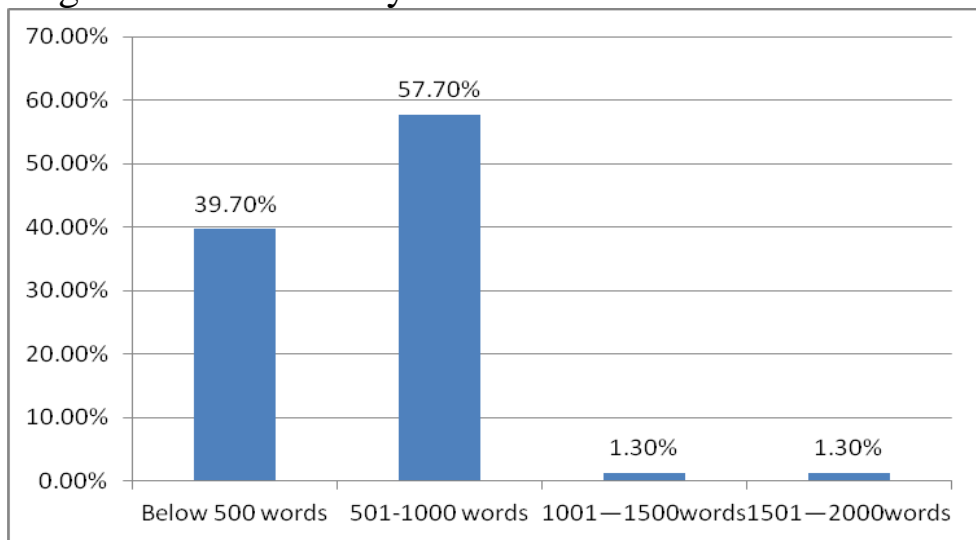

Figure 1 The length of report in China Daily 


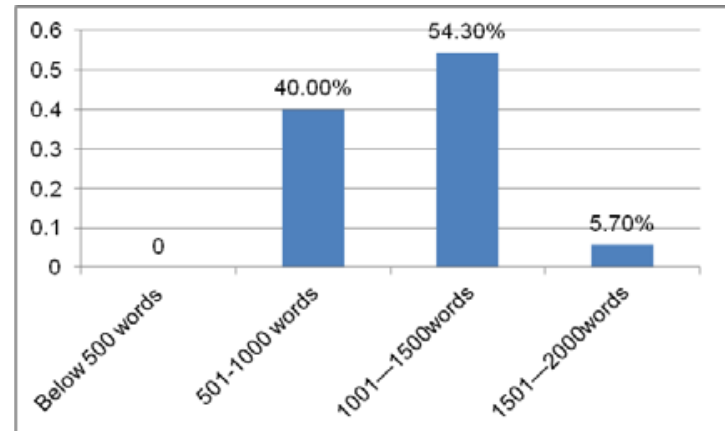

Figure 2 The length of report in New York Times

The types of news. Through statistical analysis, we found a notable feature in China Daily that the comment texts (64.1\%) were far more than the factual news reports (35.9\%) on this incident. On the contrary, factual reports (97.1\%) in the New York Times were overwhelmingly more than the comment texts (2.9\%).

News source. The choice of the news source can reflect the media's preference, tendency and even the value orientation. Through the multiple response analysis(Figure 3, Figure 4), we can find that the sources of China Daily are mainly from HK officials(23.7\%), HK residents(22.0\%).which is consistent with the news principle of proximity. Another aspect which needs to be addressed is that the objectivity of news is to balance the views of both sides. The dissident is one of the major parties in the event, yet the citation rate of it in China Daily is only 3.4\%. It can be seen that the China Daily has failed to abide by the principle of balance.

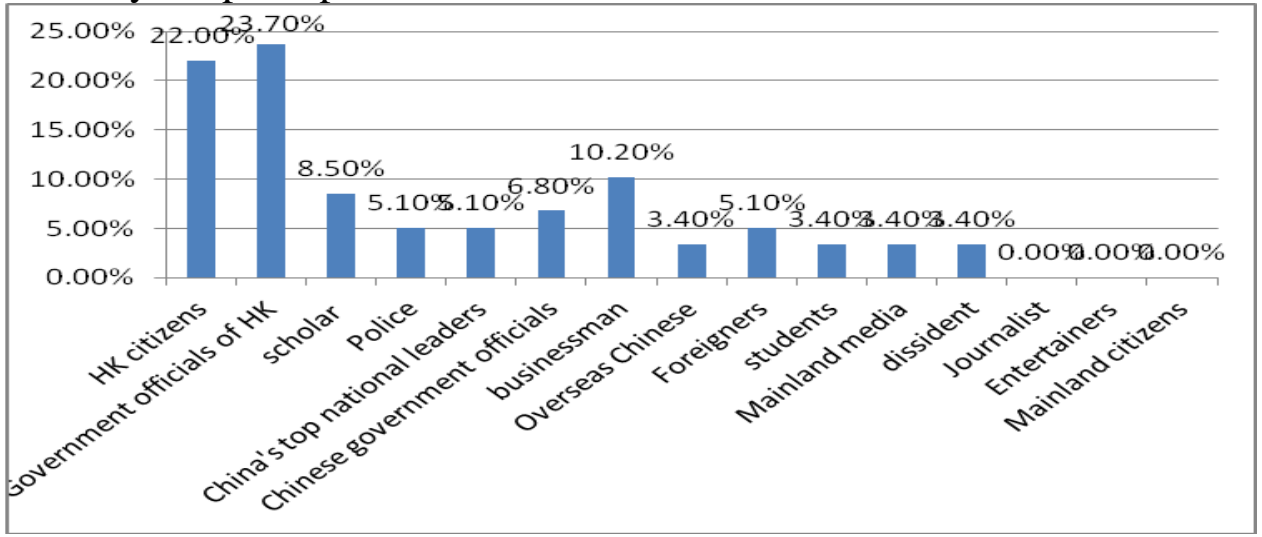

Figure 3 News source of China Daily

On the contrary, the source of New York Times is more diversified. which to some extent reflects the objectivity principle of the media. On the other hand, among all the sources cited by the New York Times, the largest one is "dissidents" (16.5\%). From this we can find that western media like to present the conflict side when involving China's internal affairs. Thus, what behind the apparent multiple sources is the substantive inequality of discourse right.

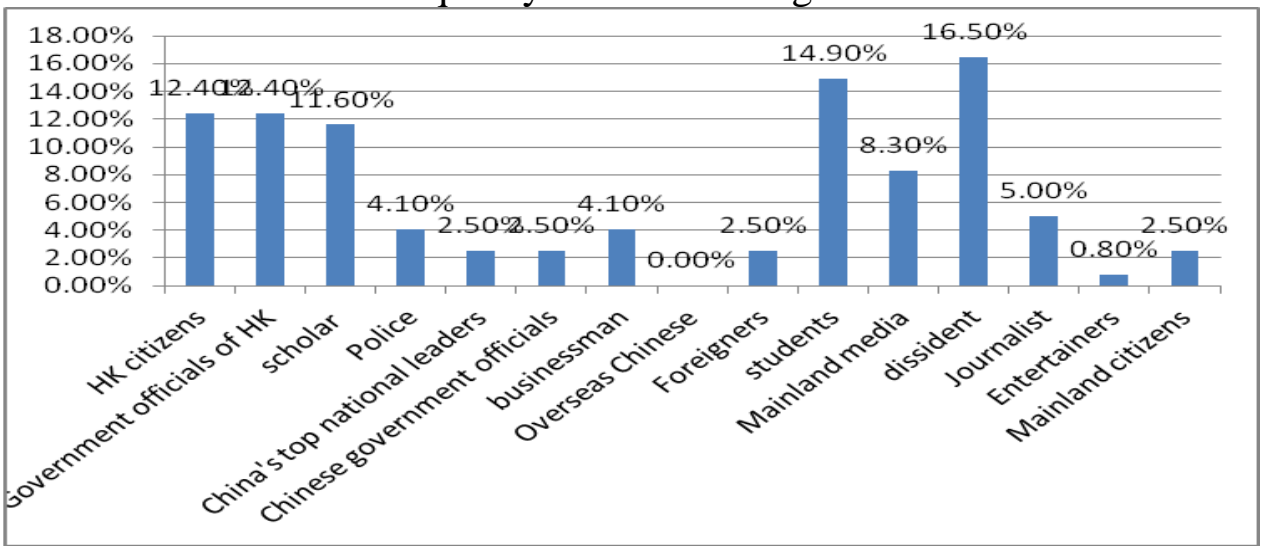

Figure 4 News source of China Daily 
Use of quotation. Statistics show that there are 28 pieces of news in China Daily, including 113 direct quotation, The per article has 4 direct quotations and there are 94 indirect quotations in China daily, and the per article has 3.4 indirect quotation. As for 34 pieces of news in New York Times, there are 186 direct quotations, so the per article has 5.5 direct quotation and there are 102 indirect quotation in it, which means the per article has 3 indirect quotation.

Theme. As can be seen from figure 5, among all the topics of China Daily's reports, The most prominent theme is "pointing out the harm and illegality of the occupy centrally incident", It can clearly reflect the position of Chinese media on "Occupy Central" incident. On the other hand, China Daily also showed different types of themes.

Compared to China Daily's multiple themes, we found that themes of New York Times represented two significant features(Figure 6).

One is more than half of the reports in New York Times have showed the action of actors of Occupy Central incident, That is to say, the New York Times focuses on the progress of the action itself, which was in sharp contrast to China Daily's themes focusing on the harm of the actions.

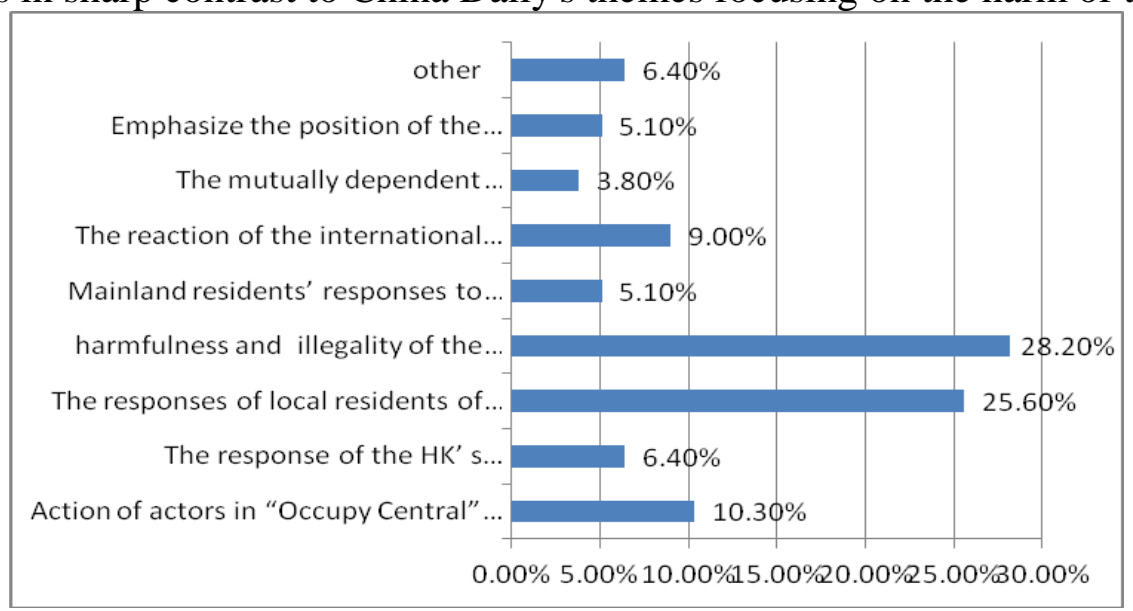

Figure 5 the theme of China Daily

Another characteristic of New York Time is that it keeps mum about the relationship between the mainland and Hong Kong.

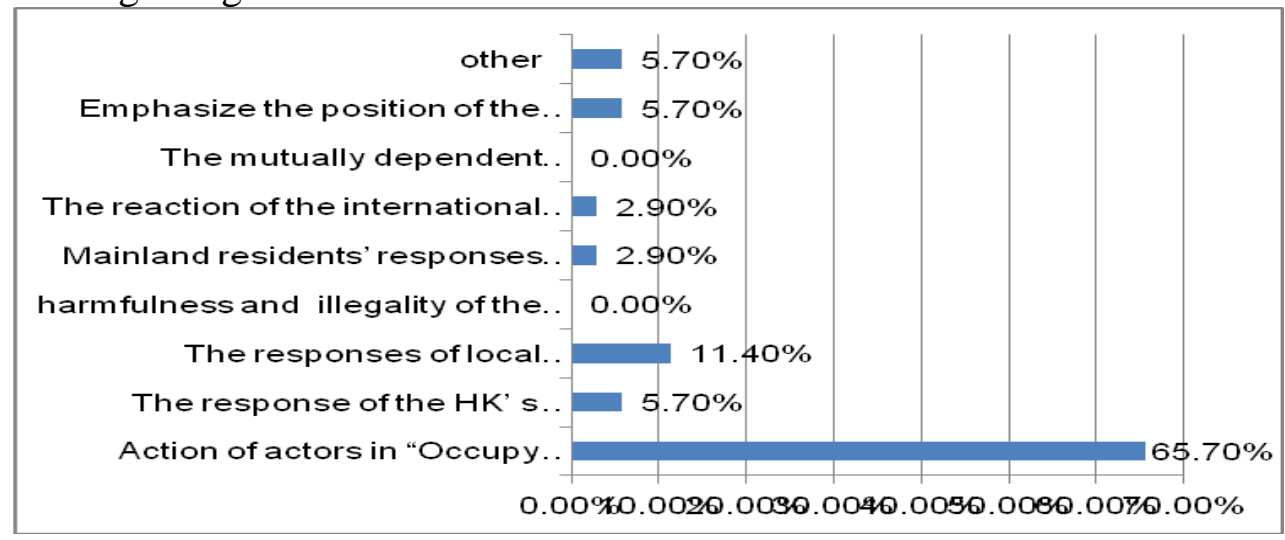

Figure 6 the theme of New York Times

Media frame. There are significant differences in the media frames of two newspaper( $x$ $=46.46, \mathrm{df}=5, \mathrm{p}<0.05)$.

From the perspective of the news frame, the China Daily mainly adopted the consequences-effect frame. That is to say, emphasized the adverse consequences that the "Occupy Central" has brought to Hong Kong's politics and economy, which is in accord with China Daily's major theme of emphasizing the harmfulness and illegality of the "Occupy Central" incident.

The New York Times used process frame to report the progress of events more often. Which coincided with the major theme of New York Times about intensively presenting the action of Occupy Central' s actors.

Compared with the New York Times' one-sided frame about "Occupy Central", the media frame of China Daily is diversified. 
Chart1: the news frame of two media

\begin{tabular}{lcc}
\hline News frame & China Daily $(\mathrm{n}=70)$ & New York Time $(\mathrm{n}=31)$ \\
Process frame & $16.7 \%$ & $80.0 \%$ \\
Outcome and effect frame & $30.8 \%$ & $2.90 \%$ \\
Advice frame & $5.1 \%$ & $8.6 \%$ \\
Explanation frame & $10.0 \%$ & $0.0 \%$ \\
Query frame & $16.7 \%$ & $5.7 \%$ \\
Rule of the law frame & $20.5 \%$ & $2.9 \%$
\end{tabular}

Except for the consequences-effect frame, China Daily also extensively used the "rule of law" frame in order to reaffirming the status of the basic law and the authority of the NPC Standing committee.

\section{Conclusion \& Discussion}

This paper analyzed the different characteristics of Chinese and Western English media on China-related reports. The study found that the length of essay in New York Times is far more than China Daily, and the number of sources cited by New York Times is also more than China Daily. which leads us to considerable reflections especially for the mainstream media that undertake the task of international communication. They should spread the claim of China in a way consistent with Western habits and thinking mode so as to speak good Chinese story and spread Chinese sound perfectly.

As for the news types, the New York Times upholds the "professionalism" convention, so the majority of its reports are dynamic news. In this type of political event related to China's internal affairs, the China Daily tends to express their views and attitudes through the comments. With a lot of comments, China Daily on behalf of the party, the government and the masses of the people showed its attitude, guided the public opinion as well as indicated a firm determination to safeguard the state's sovereignty.

The objectivity of journalism requires journalists to report news in an unbiased way, rather than just to present the opinions of one side. However, in the study we have found that although the New York Times didn't express their point of views directly, it expressed its position indirectly by carefully selecting some news sources. This behavior of over-reliance on one side source is contrary to their idea of professionalism".

A citation is a faithful record of the views of the witness and someone concerned. This study found that the average number of direct quotations in each article of China Daily is lower than that in the New York Times. Thus, as for the Chinese journalists serving in International communication media, they need to enhance their awareness of using direct speech in order to improve the authenticity and objectivity of news.

In terms of the news theme, the Western media mainly focused on the progress of the rally. The Chinese media mainly pointed out the dangers and illegality of the "Occupy Central" rallies and emphasized the importance of upholding the rule of law.

The different presentations of two media for the "Occupy Central" incident has reflected the different values and attitudes between Chinese and foreign media. Through the analysis of the report characteristic of two media, we can find some basic rule of Chinese and foreign media' reports on the China-related event and we also look forward to providing some reference for China's international communication.

\section{References}

[1] Kexu Zhang, Haiqun Zang, Gang Han, Jie He. From Media Reality to Subjective Reality. Journalism \&Communication.1999,vol,6.no.2.pp. 2-10 
[2] Gitlin, T., The whole world is watching: Mass Media in the Making and Unmaking of the New Left, Berkeley, University of California Press,1980,pp.6

[3] Entman, R. M. framing: towards clarification of a fractured paradigm. Journal of Communication. 1993, vol43, no4, pp.50-58

[4] Yang Chen. Frame Analysis: A Theoretical Concept That Needs To Be Clarified. Journal of International Communication. 2007, no.4 pp.19-22

[5] Kahneman, D.,\& tversky, A choice, values, and frames. American Psycgologist. 1984, vol39, no4. pp.341-350

[6] De vreese. C,H. The effects of frames in political television news on issue interpretation and frame salience. Journalism \& Mass Communication Quarterly . 2004,vol81,no1.pp.36-52

[7] Ghanem, S. Filling in the tapestry: The second level of agenda-setting. In Maxwell E. McCombs, Donald Lewis Shaw, David Hugh Weaver Communication and democracy :Exploring the intellectual frontiers in agenda-setting theory . Mathwah . NJ :Lawrence Erlbaum Associates.1977 pp.10. 